\title{
ANALYSIS OF DIFFERENT CLOUD SIGNATURES USING MULTIWAVELENGTH RAMAN LIDAR RETRIEVALS
}

\author{
Simona Andrei ${ }^{1}$, Flori Ţoancă ${ }^{1}$, Anca Nemuc ${ }^{1}$, Alex Dandocsi ${ }^{1,2}$, Livio Belegante ${ }^{1}$, Doina Nicolae ${ }^{1}$ \\ ${ }^{1}$ National Institute of R\&D for Optoelectronics, Bucharest-Măgurele, 077125, Romania, \\ simona.andrei@inoe.ro \\ ${ }^{2}$ University Politehnica of Bucharest, Bucharest, 060042, Romania
}

\begin{abstract}
The present study is focused on microphysics analysis of different cloud types observed by a multi-wavelength Raman lidar. Particle's content from a wide variety of cloud types, produced in various atmospheric environments, were investigated using data provided by lidar and validated using ECMWF's ERA Interim reanalysis. The results emphasized the capability of lidar instruments to detect multiple cloud layers, and to discriminate between ice particles and water droplets found within the studied clouds.
\end{abstract}

\section{INTRODUCTION}

Clouds represent one of the most important components of weather and climate system, having an extensive influence on Earth's radiation budget. Together with aerosols, they contribute with the largest uncertainty in estimating and interpretations of the Earth's changing energy budget [1]. The evolution of a cloud is determined by the balance between dynamical, radiative and microphysical processes that define the manner in which the atmospheric radiation is modulated [2]. Clouds and cloud systems are organized by largerscale circulations into different regimes such as deep convection, or midlatitude storm tracks guided by the tropospheric westerly jets [1]. Depending on the atmospheric environment features, clouds are composed of water droplets, ice crystals or a mixture of both [3]. The phase partition of condensed water into liquid droplets and ice crystals is temperature depending, but there is much uncertainty regarding the extent to which ice and liquid water coexist, and how to represent the ice-to-liquid water ratio below $0^{\circ} \mathrm{C}$. Observations have emphasized the presence of liquid water at temperatures as cold as $-30^{\circ} \mathrm{C}$ to $40^{\circ} \mathrm{C}$ [4]. Remote sensing observations were used in different campaigns to study cloud types, and their features such as liquid/ice water content or ice crystals [5]. Lidars are able to probe few tens of centimeters to a few tens of meters above cloud base where the maximum cloud supersaturation occurs [6]. Lidar depolarization was used to distinguish between liquid and solid phases of water [7]. Ice crystals, considered non-spherical particles can exhibit depolarization ratios greater than $20 \%$, and can be easily distinguished from cloud droplets or super cooled droplets with lower depolarization ratios [8].

This study aims to correlate the information from lidar observations and ERA Interim reanalysis in order to assess and validate the cloud particle types measured in different atmospheric environments.

\section{METHODOLOGY}

The observations of clouds have been performed by a multiwavelenth depolarization Raman lidar [9] located at Bucharest-Măgurele $\left(44.35^{\circ} \mathrm{N}\right.$, $\left.26.03^{\circ} \mathrm{E}, 93 \mathrm{~m} \mathrm{ASL}\right)$. Volume linear depolarization ratio (VDR) was used to discern between quasispherical particles with low depolarization ratios and non-spherical particles with higher depolarization ratios [10]. High temporal and vertical resolution of this parameter can provide information on cloud dynamics and structure. For water droplets the VDR is low, since they do not produce depolarization, while for ice crystals the VDR can go well above 40\% [11]. By using lidar VDR, a first estimation of ice-to-liquid water ratio had been extracted: $0 \%$ for water droplets to $100 \%$ for ice crystals.

ECMWF - ERA Interim reanalysis data [12] were used to investigate the meteorological context and the atmospheric behavior with respect to the cloud particles (ice, super cooled water droplets and water droplets). The analysis has been focused on profiles of temperature $(\mathrm{T})$, specific cloud ice 
water content (CIWC) and specific cloud liquid water content (CLWC).

\section{RESULTS}

Three cases of different cloud types were investigated in order to establish the correlations between lidar's optical parameters and meteorological parameters.

\subsection{Study case 1 (May $16^{\text {th }} 2014$ )}

Lidar measurements performed on May $16^{\text {th }} 2014$ spotted the presence of a cloud with a gradual vertical expansion (Figure 1). The cloud base had a fast decreasing from 5 to $2 \mathrm{~km}$ altitude and, at the end of measurements lidar has detected the initiation of precipitation. Time series of VDR show values ranging from 6 to $18 \%$ corresponding to water droplets up to $35 \%$ corresponding to ice crystals.
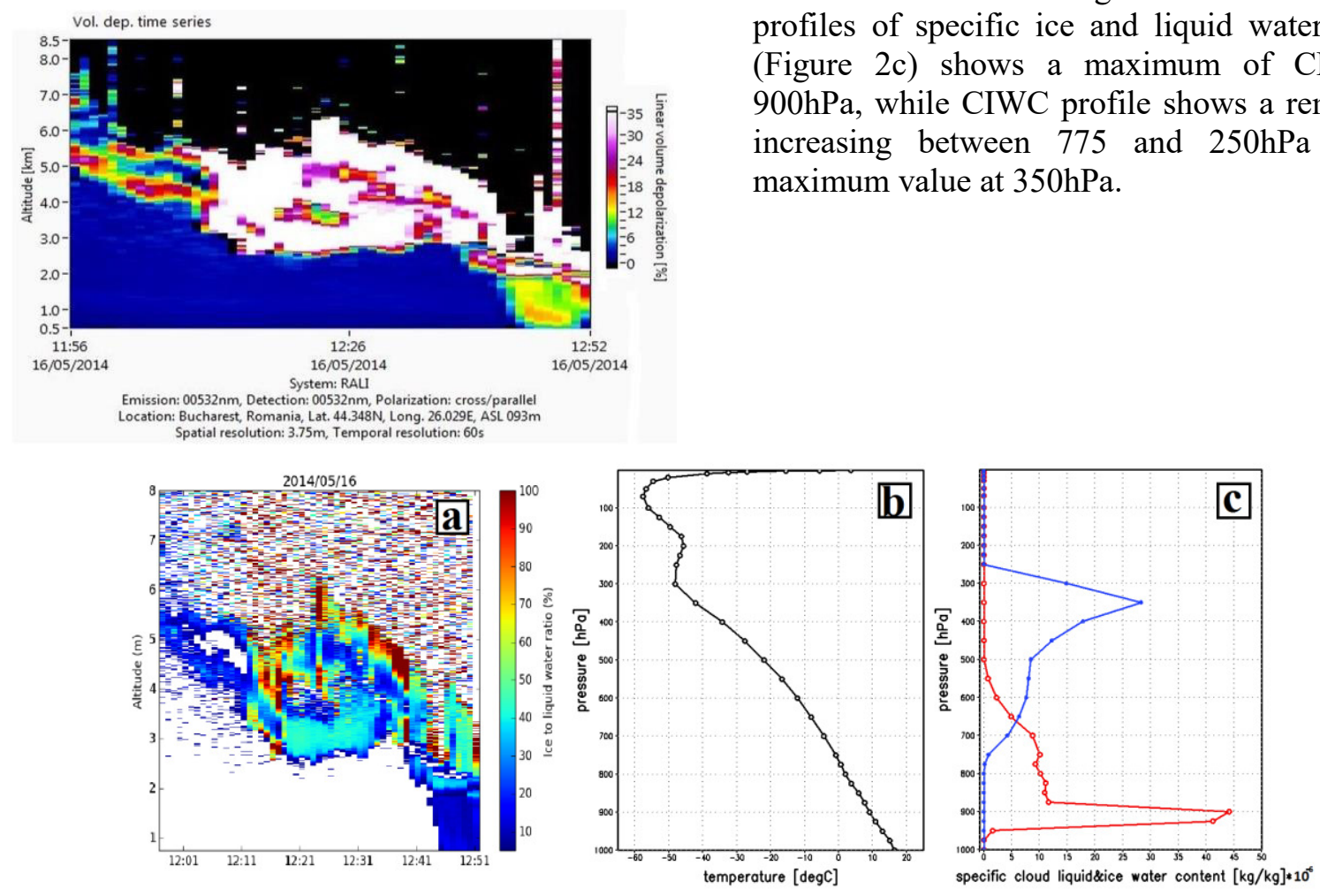

Figure 2 Time series of ice to liquid water ratio from lidar measurements (a), profile of $T^{0} C(b)$ and $C I W C$ (blue line) \& CLWC (red line) (c) from ECMWF ERA - Interim reanalysis for May 16, 2014 [12TC]

\subsection{Study case 2 (May $\left.14^{\text {th }}, 2015\right)$}

Lidar measurements performed during the evening hours of May $14^{\text {th }}, 2015$ (Figure 3) had noticed the passing of a cloud with a decreasing
Figure 1 Lidar time series of VDR for May $16^{\text {th }} 2014$

Meteorological analysis had revealed the presence of a strong cyclonic cut-off with direct influence on Romanian territory. Air circulation had enhanced the warm and humid air mass advection over Bucharest-Măgurele (not shown here) which enabled the development of a Cumulonimbus cloud.

The typical shape of the cloud development with updrafts and downdrafts passing the measurement site is emphasized in Figure 2a. Ice-to-liquid water ratio indicates the presence of water droplets (0-20\%) within the anvil cloud and precipitation regions, while a mixture of water droplets, super cooled water and ice crystals (20$100 \%$ ) has been observed between 12:11 and 12:41 UTC. Thermal profile for BucharestMăgurele (Figure $2 b$ ) shows a strong decreasing with the altitude reaching $-49^{\circ} \mathrm{C}$ on $300 \mathrm{hPa}$. The profiles of specific ice and liquid water content (Figure 2c) shows a maximum of CLWC at $900 \mathrm{hPa}$, while CIWC profile shows a remarkable increasing between 775 and $250 \mathrm{hPa}$ with a maximum value at $350 \mathrm{hPa}$.

base from 10 to $2 \mathrm{~km}$. Time series of VDR show high values between 18:00 and 19:00 UTC time interval.

Time series of ice-to-liquid water ratio (Figure 4a) reveals the presence of a pre-frontal cumuliform 
development, with values ranging from 0 to $60 \%$ corresponding to the presence of warm and cooled water droplets.

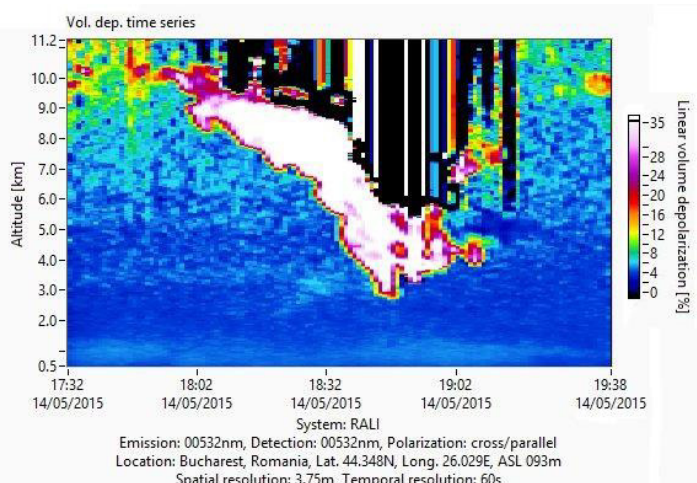

Figure 3 Lidar time series of VDR for May $14^{\text {th }} 2015$

Thermal profile (Figure 4b) emphasizes the presence of warm dry air within the lower troposphere $(0$ to $800 \mathrm{hPa})$. The thermal decreasing with the altitude reached $-60^{\circ} \mathrm{C}$ at the top of troposphere. Vertical distribution of specific ice and liquid water content (Figure 4c) indicates two layers with increasing values: one, between 800 and $500 \mathrm{hPa}$, and the other one, between 400 and $200 \mathrm{hPa}$. Within the first layer CLWC presents a maximum value at $650 \mathrm{hPa}$ and a maximum value for CIWC at $600 \mathrm{hPa}$. A weaker peak of CIWC is indicated within the second layer, between 300 and $25 \mathrm{hPa}$.
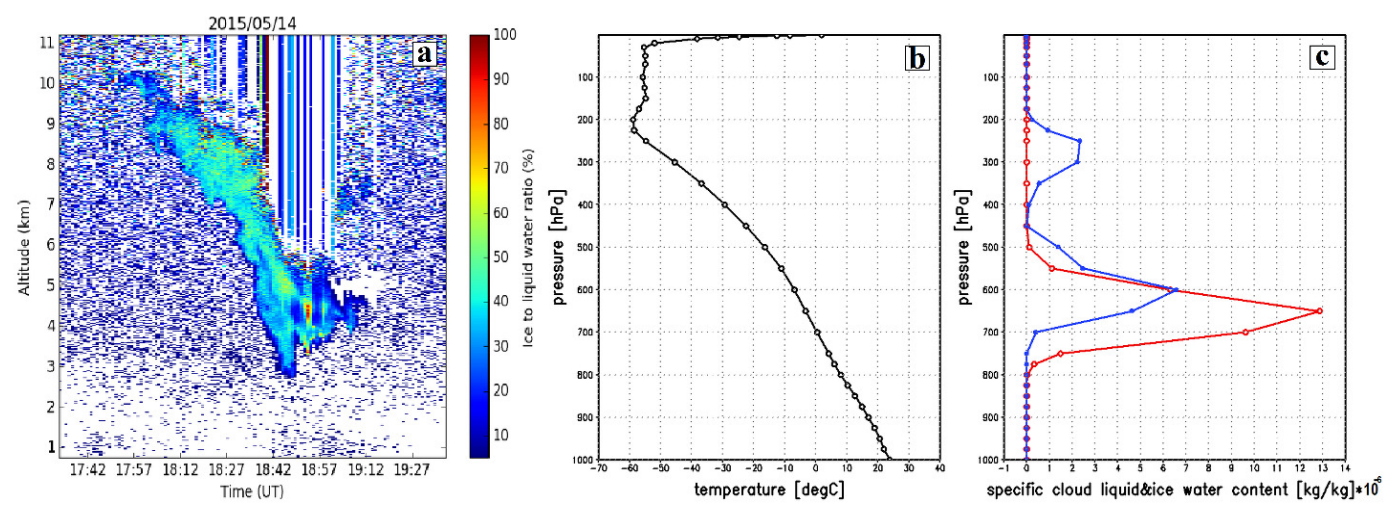

Figure 4 Time series of ice to liquid water ratio from lidar measurements (a) profile of $T^{0} \mathrm{C}$ (b) and $C I W C$ (blue line) \& CLWC (red line) (c) from ECMWF ERA - Interim reanalysis for May 14, 2015 [18TC]

\subsection{Study case 3 (May $19^{\text {th }}, 2016$ )}

Measurements performed on May $19^{\text {th }}, 2016$ emphasize the presence of Cirrus cloud having its base at around $8 \mathrm{~km}$ at the beginning of the measurement and decreasing at around $6.5 \mathrm{~km}$ during the last hour. The VDR (Figure 5) shows low values (4 to 14\%) indicating the presence of spherical particles (water droplets). At the level of $4 \mathrm{~km}$ a Cumulus cloud can be observed (red circle) developed in the middle of an aerosol layer present between 2.5 and $4 \mathrm{~km}$ (not shown here).

Ice to liquid water ratio (Figure 6a) shows low values (0 to 20\%) indicating the dominance of cold water particles. Thermal profile (Figure 6b) emphasizes the presence of warm dry air within the lower troposphere $(0$ to $800 \mathrm{hPa})$ and the decreasing with the altitude reached $-56^{\circ} \mathrm{C}$ at the tropopause level.

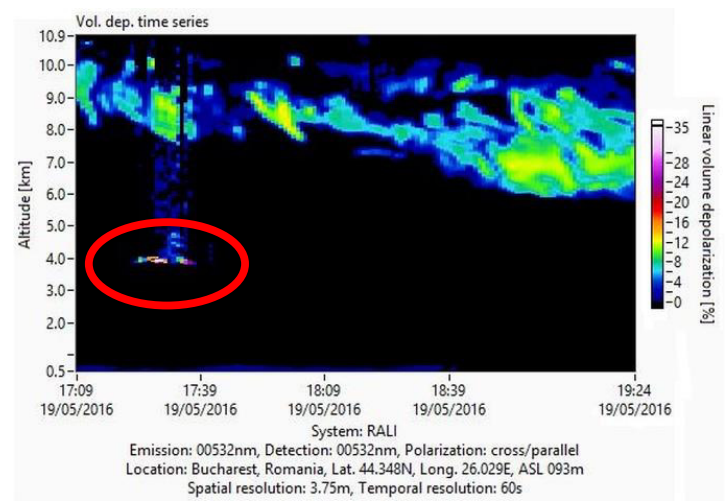

Figure 5 Lidar time series of VDR for May $19^{\text {th }} 2016$

Vertical distribution of atmospheric humidity (Figure 6c) indicates increasing values within two layers, first one - between 850 and $550 \mathrm{hPa}$, and the second one - between 400 and $250 \mathrm{hPa}$. Within the first layer, CIWC presents a maximum value at $600 \mathrm{hPa}$ and a maximum value of CLWC at $650 \mathrm{hPa}$. Within the second layer, discreet peak of CIWC content presents a maximum at $350 \mathrm{hPa}$ 

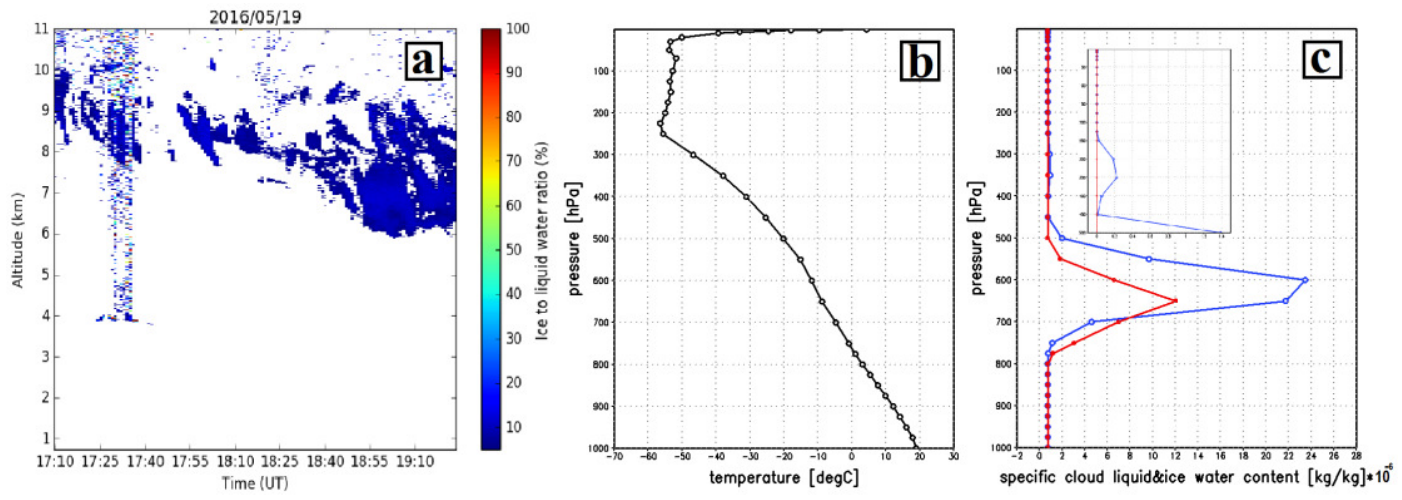

Figure 6 Time series of ice to liquid water ratio from lidar measurements (a profile of $T^{0} C$ (b) and CIWC (blue line) \& CLWC (red line) (c) from ECMWF ERA - Interim reanalysisfor May 19 $9^{\text {th }}, 2016$ [18TC]

\section{CONCLUSIONS}

The profiles presented in this study shows the capability of lidar instruments to detect different cloud signatures. Based on the VDR the lidar instruments are able to distinguish between spherical (water droplets) and non-spherical particles (ice particles). The ice to liquid water ratio profiles from lidar measurements and specific cloud ice and liquid water content from reanalysis data are in good agreement. Synoptic meteorological contexts explain well the cloud types detected by lidar. Vertical distributions of cloud particles for the analyzed cases are consistent with those mentioned by theory [3].

\section{ACKNOWLEDGEMENTS}

The research leading to these results has received funding from ANCS Core program, project no. 16.40.01.01 and the E.U. Horizon2020 Programme (GA 692014) - ECARS.

\section{References}

[1] Intergovernmental Panel on Climate Change, 2013: Chapter 7 of the $5^{\text {th }}$ assessment report of the Intergovernmental Panel on Climate Change.

[2] Shuppe, M.D., et al., 2008: A focus on mixedphase clouds: The status of ground-based observational methods, Bull. Amer. Meteor. Soc., 89, 1549-1562.

[3] Pruppacher, H. R., Klett, J. D., 1997: Microphysics of clouds and precipitation (2nd ed.), Springer.

[4] Hogan, R. J., et al., 2003: Characteristics of mixed-phase clouds. I: Lidar, radar and aircraft observations from CLARE'98, Q. J. $R$. Meteorol. Soc., 129 (592), 2089-2116.

[5] Myagkov, A., et al., 2016: Relationship between temperature and apparent shape of pristine ice crystals derived from polarimetric cloud radar observations during the ACCEPT campaign, Atmos. Meas. Tech., 9, 3739-3754.

[6] Bühl, J., et al., 2013: Towards a quantitative characterization of heterogeneous ice formation with lidar/radar: Comparison of CALIPSO/CloudSat with ground-based observations, Geophys. Res. Lett., 40, 44044408, doi:10.1002/grl.50792.

[7] Sassen, K., 1991: The polarization lidar technique for cloud research: a review and current assessment, Bull. Am. Meteor. Soc., 72, 1848-1866.

[8] Pal, S. R., and Carswell, A. I., 1973: Polarization properties of lidar backscattering from clouds, Appl. Optics, 12 (7), 1530-1535.

[9] Klett, J. D., 1985: Lidar inversion with variable backscatter/extinction ratios, Appl. Optics, 24, 1638-1643.

[10] Freudenthaler, V. 2016: About the effects of polarising optics on lidar signals and the $\Delta 90$ calibration, Atmos. Meas. Tech., 9, 41814255.

[11] Gro $\beta$, S. et al.., 2013: Aerosol classification by airborne high spectral resolution lidar observations, Atmos. Chem. Phys., 13(5), 2487-2505.

[12] Dee D.P., et al., 2011: The ERA-Interim reanalysis: configuration and performance of the data assimilation system. Q.J. R. Meteorol. Soc. 137: 553-597. 